\title{
Margrét Oddsdóttir, M.D. (1955-2009)—An Influential Woman in Surgery
}

\author{
Dana K. Andersen ${ }^{1}$
}

Accepted: 5 July 2021 / Published online: 16 July 2021

(C) This is a U.S. government work and not under copyright protection in the U.S.; foreign copyright protection may apply 2021

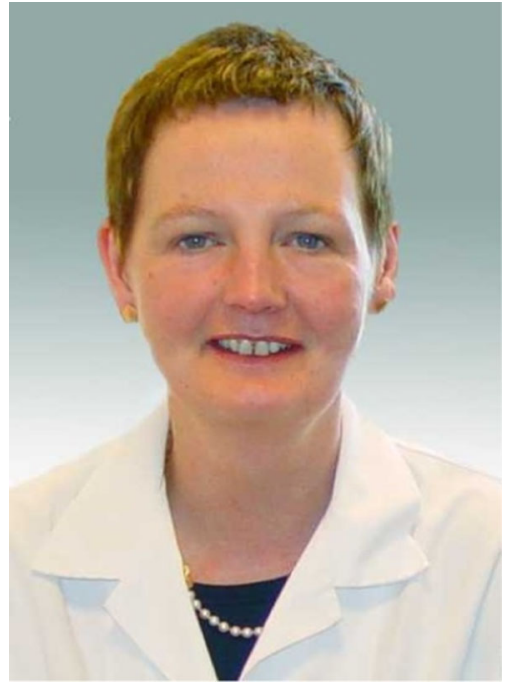

Margrét grew up in the small fishing village of Isafjördur on the northwest coast of Iceland. She loved the outdoors and enjoyed beating her brothers in games. She attended the University in Reykjavik and then its medical school where she decided she should become a surgeon. Iceland is a small country, and graduates who wished to pursue surgical residency beyond the intern or junior resident level had to complete their training outside the country. Dr. Oddsdóttir chose to go to Yale where she

Dana K. Andersen

dana.andersen@nih.gov

1 Division of Digestive Diseases and Nutrition, National Institute of Diabetes and Digestive and Kidney Disease, National Institutes of Health, 6707 Democracy Blvd., 6th Floor, Bethesda, MD 20892, USA enjoyed the admiration and friendship of her colleagues and faculty. During her training, laparoscopic surgery was in its infancy, and she was inspired by its innovation and potential. After her chief residency, she moved to Atlanta in 1992 to become the first laparoscopic surgery fellow in the country under the mentorship of John Hunter. Her husband Jon and son Oddur accompanied her, and a second son Siggi was born while she was there.

In 1994, Dr. Oddsdóttir and her family returned to Reykjavik where she joined the general surgery faculty specializing in advanced gastrointestinal surgery and where she introduced laparoscopic surgery to her country. In 2002, she became Professor and Chief of General Surgery at Landspitali, the National University Hospital in Reykjavik. She was a gifted teacher who received award recognition from her students and often traveled to medical meetings, becoming friends with many leaders in minimally invasive surgery internationally. She was particularly devoted to inspiring young women to pursue graduate training in surgery and began a process of identifying the most talented women who were then sent for surgical training in the USA, and occasionally Sweden, with her personal endorsement. At a time when most surgical trainees were male, Dr. Oddsdóttir, who was known as "Magga" by her friends and colleagues, was responsible for at least eight women surgeons who completed their training and returned to Iceland. Today the number of female and male surgeons in Iceland is about equal, largely due to her efforts.

Her home exuded the same high energy as her work in the hospital. Her husband Jon was a journalist and popular radio talkshow host. The conversations were diverse, eclectic and passionate, and usually fueled by good strong coffee which Magga loved. In fact, in a long case in the OR, Magga would stop after the critical portion and have 
the circulator bring in cups of her favorite coffee together with sugar cubes and straws so that the team could stop for a minute, have the circulator slip a cube and a straw under their masks, and sip some coffee to prepare to finish their task. She was a complete enthusiast in everything that she did and her energy was infectious. Today there is a group of young Icelandic women surgeons who call themselves "Möggunar" or "The Maggas!" They meet on a regular basis and have a good time and Magga would have loved that.

Immensely proud of her Viking heritage, Dr. Oddsdóttir was fond of quoting from the Hávamál, an ancient Viking poem. One quote that she was fond of, and which she wrote after the death of Elton Cahow, the Chief of General Surgery at Yale who had recruited her, was "a man who has personal integrity is better placed than one whose life is spent impressing others. Nothing can take such a man's life away, for although death is inescapable, his posthumous reputation will never die." Sadly, Magga's death from advanced breast cancer was preceded 18 months before by the death of Jon from pancreatic cancer. Magga's own reputation for personal integrity and for being a model academic surgeon will never die. In 2010, the ninth edition of Schwartz's Principles of Surgery was dedicated to Margrét Oddsdóttir and in 2013 The Society of American Gastrointestinal Endoscopic Surgeons established the SAGES Foundation Margrét Oddsdóttir Traveling Fellowship, bringing a (preferentially) female surgeon and a teammate from outside the USA to the annual SAGES meeting. Teamwork came easy for Margret, because nearly everyone wanted to be part of her team.

Publisher's Note Springer Nature remains neutral with regard to jurisdictional claims in published maps and institutional affiliations. 